\title{
Intervenção Grupal em Pacientes com Obesidade e seus Familiares: Relato de Experiência
}

Group Intervention to Obesity Patients and Their Families: Experience Report

Grupo de Intervención a los Pacientes con Obesidad y sus Familias: Informe de la Experiência

Aline Attene de Almeida Bayer, Camila Carrascoza Vasco \& Sandra Ribeiro de Almeida Lopes Universidade Presbiteriana Mackenzie

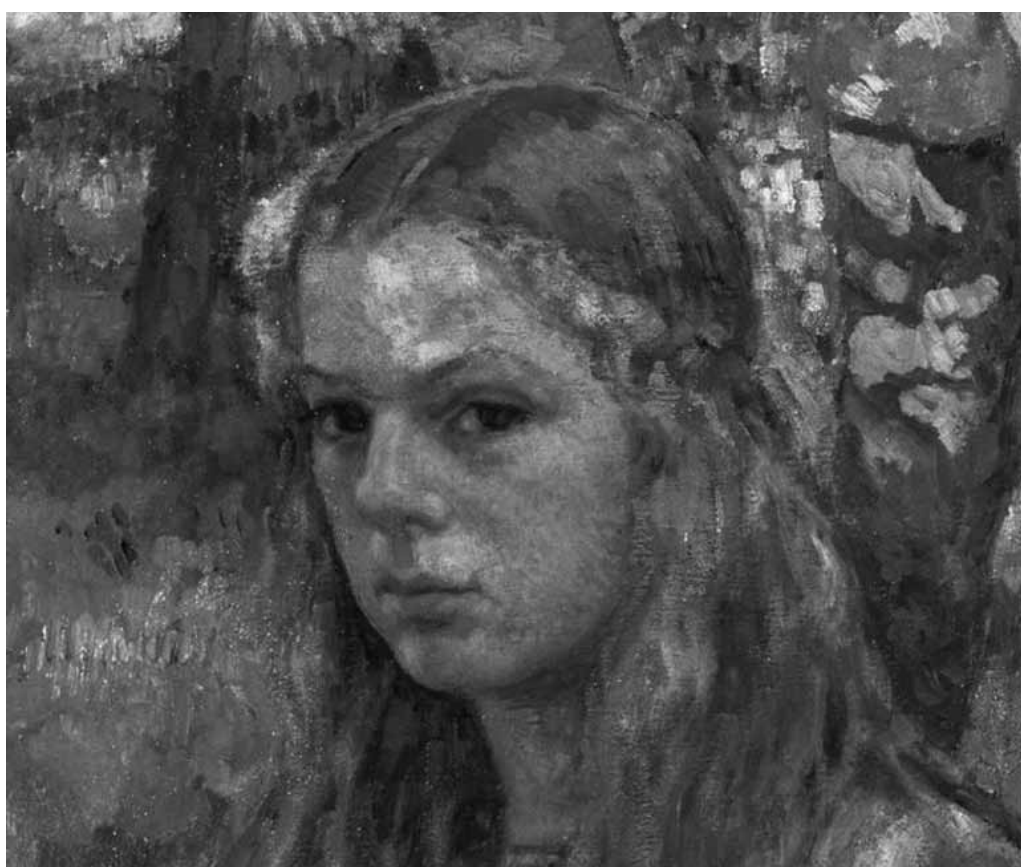


Resumo: A modalidade de atendimento em grupo no hospital é uma forma de trabalho que permite interação e troca entre os participantes, caracterizando-se como espaço de acolhimento às angústias frente a um quadro clínico. A experiência relatada consistiu na realização simultânea de dois grupos, um de pacientes entre 8-15 anos, com quadro de obesidade e sobrepeso, e outro de pais/responsáveis. O objetivo geral foi proporcionar espaço para abordar aspectos emocionais e comportamentais associados ao quadro clínico e estabelecer relações com as dificuldades na adesão ao tratamento. Realizaram-se sete encontros semanais, com atividades que propiciaram reflexão sobre questões como: autoestima, ansiedade, limites e dificuldades na manutenção das dietas e das atividades físicas regulares. A proposta possibilitou compartilhar vivências, debater atitudes, abordar insatisfações e desconfortos e perceber a necessidade de se responsabilizarem pelo tratamento através da mudança de determinados comportamentos. A opção por grupos paralelos permitiu notar mudanças nas relações entre pais/responsáveis e pacientes que contribuíram para melhor resposta ao tratamento. Tal experiência ilustrou a importância de considerar os aspectos emocionais envolvidos na obesidade, favorecendo uma visão mais abrangente do paciente.

Palavras-chave: Grupos. Obesidade. Emoções. Família.

Abstract: The psychological group modality inside the hospital is a way of work that allows interaction and exchange among participants, characterizing itself as a shelter environment to the anguish that is present in a clinical condition. The related experience consisted in the work of two groups: obese patients between 8-15 years old and a group of parents. The main goal of the work groups was to serve as a place to approach the emotional aspects and the challenges in treatment adherence. Seven meetings took place, weekly, with activities that provided space of reflection to matters as: self-esteem, anxiety, limits and difficulties in maintaining the diet and regular physical activity. The proposal made it possible to share experiences, discuss attitudes, address grievances and discomfort and notice the need to take responsibility in the process by changing certain behaviors. The option for parallel groups allowed the notice of changes in relationships between parents and patients, contributing to a better response on the treatment. The experience showed the importance of taking into account the emotional aspects present in obesity, providing a wider vision of the patient.

Keywords: Groups. Obesity. Emotions. Family.

Resumen: La modalidad de atendimiento en grupo en el hospital es una forma de trabajo que permite interacción e intercambio entre los participantes, caracterizándose como espacio de acogida a las angustias frente a un cuadro clínico. La experiencia relatada consistió en la realización simultánea de dos grupos, uno de pacientes entre 8-15 años, con cuadro de obesidad y sobrepeso, y otro de padres/responsables. El objetivo general fue proporcionar espacio para abordar aspectos emocionales y de comportamiento asociados al cuadro clínico y establecer relaciones con las dificultades en la adhesión al tratamiento. Se realizaron siete encuentros semanales, con actividades que propiciaron reflexión sobre cuestiones como: autoestima, ansiedad, límites y dificultades en el mantenimiento de las dietas y de las actividades físicas regulares. La propuesta posibilitó compartir vivencias, debatir actitudes, abordar insatisfacciones y faltas de confort y percibir la necesidad de responsabilizarse por el tratamiento a través de la mudanza de determinados comportamientos. La opción por grupos paralelos permitió notar mudanzas en las relaciones entre padres/ responsables y pacientes que contribuyeron para mejor respuesta al tratamiento. Tal experiencia ilustró la importancia de considerar los aspectos emocionales involucrados en la obesidad, favoreciendo una visión más amplia del paciente.

Palabras clave: Grupos. Obesidad. Emociones. Familia.

O presente artigo tem como objetivo geral relatar e discutir a experiência de uma intervenção psicológica grupal em pacientes pediátricos com quadro de obesidade e sobrepeso e de seus familiares em um hospital infantil na cidade de São Paulo. O trabalho foi realizado por uma dupla de estagiárias do último ano do curso de Psicologia da Universidade Presbiteriana Mackenzie, supervisionadas pela professora da área e orientadas pela psicóloga da instituição hospitalar.

O convite para a participação da Psicologia no trabalho com jovens surgiu a partir da demanda de um trabalho interdisciplinar, uma vez que os pacientes eram acompanhados exclusivamente pelas equipes de endocrinologistas e nutricionistas da instituição, que, na prática, observavam a baixa adesão ao tratamento por parte dos jovens e pequena colaboração de seus familiares nesse processo. As maiores dificuldades dos jovens consistiam em seguir corretamente as dietas propostas, realizar os exames necessários, comparecer às consultas agendadas e dar continuidade às atividades físicas sugeridas, o que resultava na manutenção ou no aumento do peso. 
Segundo Kochi e Monte (2006), 17,6 milhões de crianças até 5 anos de idade já apresentaram excesso de peso, e o aumento de peso na infância duplicou desde 1980, enquanto triplicou na adolescência.
O trabalho psicológico nesse contexto teve a função de ampliar a percepção do paciente em relação ao seu corpo, à sua autoestima, as suas relações interpessoais e aos fatores emocionais e comportamentais presentes no processo de tratamento. Além disso, objetivou fornecer informações sobre a doença e sobre as formas de autocuidado e de alternativas para conseguir melhora em sua saúde e qualidade de vida.

Partindo da consideração que a família é vista como um sistema em que as pessoas vivem no mesmo espaço e mantêm relações significativas de interdependência entre os vários subsistemas familiares, entende-se que o aspecto fundamental desse sistema está no fato de que a pessoa que apresenta problemas é apenas uma representante circunstancial de alguma disfunção no sistema familiar (Cerveny, 2004). A autora complementa que a enfermidade é vista como parte de uma dinâmica de ajustes adaptativos constantes entre os sistemas biológicos, psicológicos e interpessoais. Sendo assim, observou-se a importância de se realizar uma intervenção que contemplasse, ao mesmo tempo, pacientes e familiares (pais/ responsáveis), possibilitando também a estes últimos um espaço onde pudessem discutir os aspectos relacionais, comportamentais e emocionais associados ao enfrentamento da obesidade e ao seu tratamento.

Vasques, Martins e Azevedo (2004) afirmam que a obesidade, por sua caracterização e etiologia multifatorial, é uma condição que tem merecido atenção e estudos de diversas áreas de especialidades, particularmente a psiquiatria e a Psicologia. Ballone e Moura (2007) colocam que há duas tendências sociais cruciantes para pessoas acima do peso ideal; uma é a grosseira e desumana discriminação estética, e a outra é encarar o obeso como uma pessoa que não tem força de vontade e que é assim porque é preguiçoso. Algumas vezes, isso gera preconceito em relação à pessoa obesa e maiores dificuldades para relacionamentos sociais e afetivos. Segundo os autores, a obesidade é considerada hoje uma doença crônica que provoca ou acelera o desenvolvimento de muitas outras doenças. Vários fatores podem contribuir para causar a obesidade, como: doenças endocrinológicas, alterações genéticas, idade, ausência de atividade física e comportamento alimentar alterado e inadequado, entre outros.

A transmissão familiar da obesidade é bem conhecida. No entanto, membros da mesma família estão expostos a hábitos culturais e dietéticos que acabam influenciando, sobremaneira, o ganho de massa corporal. $\mathrm{Na}$ infância, o manejo pode ser ainda mais difícil do que na fase adulta, pois está relacionado a mudanças de hábitos e a disponibilidade dos pais, além de uma falta de entendimento da criança quanto aos danos da obesidade. Isso evidencia que, além da herança genética, a influência ambiental também acaba desempenhando papel importante no desenvolvimento da obesidade.

Segundo Kochi e Monte (2006), 17,6 milhões de crianças até 5 anos de idade já apresentaram excesso de peso, e o aumento de peso na infância duplicou desde 1980, enquanto triplicou na adolescência. A explicação de Ballone e Moura (2007) referese ao fato de que a vida moderna tem criado mais condições para o desenvolvimento de obesidade em crianças. Atualmente, elas ficam muito em casa, em seus quartos, sentadas ou deitadas na cama, jogam videogame, navegam pela internet, assistem vídeos ou estão ligadas na TV. Pesquisas têm revelado que as crianças entre 8 e 16 anos passam várias horas em frente à televisão diariamente. Esses estudos procuram relacionar o hábito de ver TV com a obesidade infantil, já que são diminuídos os exercícios físicos. A criança e o adolescente tendem a ficar obesos quando sedentários, e a própria obesidade pode torná-los ainda mais sedentários. A atividade física, mesmo espontânea, é importante na composição corporal por aumentar a massa 
óssea e prevenir a osteoporose e a obesidade (Mello, Luft, \& Meyer, 2004).

Hábitos sedentários, como assistir televisão e jogar video game, contribuem para uma diminuição do gasto calórico diário. Klesges, Shelton e Klesges (1993), em sua pesquisa sobre os efeitos que a atividade de assistir televisão traz para crianças e adolescentes, observaram importante diminuição da taxa de metabolismo de repouso no momento em que as crianças assistiam a determinado programa de televisão, sendo ainda menor essa taxa nas obesas. O metabolismo de repouso também pode influenciar a ocorrência de obesidade, portanto, os autores ressaltaram a importância de um aumento da atividade física e também de menor ingestão alimentar, visto que, com a atividade física, o indivíduo tende mesmo a escolher alimentos menos calóricos.

Há estudos que relacionam o tempo gasto assistindo televisão e a prevalência de obesidade. A taxa de obesidade em crianças que assistem menos de 1 hora diária é de $10 \%$, enquanto o hábito de persistir por 3 , 4, 5 ou mais horas por dia vendo televisão está associado a uma prevalência de cerca de $25 \%$, $27 \%$ e $35 \%$, respectivamente. A televisão ocupa horas vagas em que a criança poderia estar realizando outras atividades.

A criança frequentemente come na frente da televisão, e grande parte das propagandas oferecem alimentos não nutritivos e ricos em calorias. Grazini e Amâncio (1998) fizeram um estudo a respeito desse tema, investigando se haveria ligação entre os hábitos alimentares e os comerciais veiculados na televisão, e analisaram o teor das propagandas em horários de programas para adolescentes. Verificaram que a maioria delas (53\%) era de lanches e refrigerantes, que exercem grande influência no hábito alimentar dos adolescentes.
Cardoso e Carvalho (2007) ressaltam que a obesidade está também relacionada a fatores psicológicos como o controle, a percepção de si, a ansiedade e o desenvolvimento emocional, e, por isso, demanda uma investigação sistemática. Para Ferriani, Dias, Silva e Martins (2005), uma característica importante em pacientes obesos é a depreciação da própria imagem física, pois sentem-se inseguros em relação aos outros e imaginam que estes os veem com hostilidade e desprezo, já que, nessa fase, a construção da identidade pessoal inclui necessariamente a relação com o próprio corpo.

Em pesquisa realizada por Carvalho, Cataneo, Galindo e Malfará (2005), verificou-se que as crianças obesas apresentam um conceito de seus corpos que não é totalmente negativo. Embora estivessem majoritariamente incomodadas com sua aparência, tendiam a concordar com as afirmações positivas sobre certas características, como ter olhos bonitos, ter um rosto agradável e ser bonito. Complementarmente, o acesso a esses autojulgamentos auxilia os profissionais que atendem essas crianças a compreendê-las, buscando recursos que possam melhor orientá-las no processo de adesão a um programa de intervenção.

Além disso, Allon (1979), em seu artigo sobre a autopercepção do estigma do excesso de peso, afirma que adolescentes com sobrepeso frequentemente se referem ao peso como um fator agravante na interação social, pois não se sentem aceitos e sofrem discriminações que interferem em seus relacionamentos sociais e afetivos. Gomes (1994) afirma que o adolescente chega a sentir-se marginalizado na sociedade atual, isso devido à não aceitação do seu corpo também por parte dos outros, o que faz com que se preocupe cada vez mais com sua imagem, tentando alcançar o ideal de beleza imposto culturalmente.

Outeiral (2003) coloca que as modificações do corpo são, muitas vezes, vividas pelo 


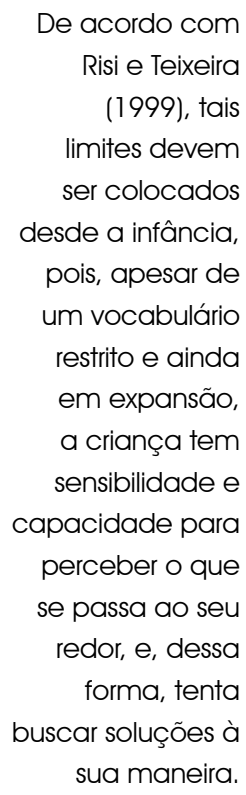

adolescente como invasoras e ameaçadoras, e que os distúrbios de alimentação podem representar tentativas de assumir ativamente (obter controle) as transformações que sofrem passivamente, visto que estarão na dependência principalmente de fatores hereditários. Os adolescentes sofrem quando não detêm o controle de uma situação. Dessa maneira, aqueles que se deparam com a obesidade têm muitos problemas quanto à aceitação de sua autoimagem, à valorização do próprio corpo e à aceitação do grupo.

Uma vez que o adolescente não detém o controle das transformações por que passa, torna-se necessário um controle externo, geralmente exercido pela família. No caso do quadro de obesidade, esse controle pode ser manifestado através de limites bem estabelecidos. De acordo com Risi e Teixeira (1999), tais limites devem ser colocados desde a infância, pois, apesar de um vocabulário restrito e ainda em expansão, a criança tem sensibilidade e capacidade para perceber o que se passa ao seu redor, e, dessa forma, tenta buscar soluções à sua maneira. A reação de agressão e de falta de limites se transforma em um pedido de socorro.

A questão do limite no desenvolvimento de uma criança é complexa, e são justamente aqueles que cuidam dela os responsáveis por sua adaptação às regras. A dificuldade pode estar no fato de que, ao tentarem impor limites aos filhos, terão que lidar com suas próprias questões e problemas relacionados a esses limites, atualizando-os e revivendoos da maneira como foram transmitidos. Carvalho e Cardoso (2007) afirmam que é a insatisfação com a saúde física, aliada às preocupações com a dinâmica emocional da criança, que fazem com que os pais se mobilizem para buscar ajuda para seus filhos.

Outro fator de preocupação dos profissionais de saúde é a adesão a propostas de tratamento. Segundo Denzer, Reithofer, Wabitsch e
Widhalm (2004), a adesão a propostas de manejo da obesidade infantil é baixa, e constitui uma das grandes dificuldades para o tratamento. O estudo de Mello, Luft e Meyer (2004) concluiu que 50\% dos adolescentes já haviam realizado dieta para emagrecer em algum momento de suas vidas, e ressalta o frequente insucesso obtido nas tentativas de redução da obesidade. A realização de dietas prévias a um tratamento foi recentemente apontada como fator preditivo de baixa adesão, acrescentando-se que o ambiente familiar é um fator importante no manejo da obesidade infantil. No presente estudo, foi verificado que $71,1 \%$ das crianças e adolescentes tinham a obesidade presente na família.

Levando-se em consideração esses dados, optou-se por um atendimento grupal visando à troca de vivências entre os participantes de cada grupo, já que essa forma de atendimento dá sustentação à fragilidade do participante e é continente para seus problemas e angústias relacionadas ao quadro de obesidade. De acordo com Toledo (2006), o grupo funciona como um potencial de apoio e de contato; além disso, pode permitir uma experiência de reapoio do desenvolvimento psíquico para aqueles cujos primeiros apoios foram insuficientes ou inadequados. O autor afirma ainda que essa abordagem grupal tem se mostrado eficaz, pois os participantes apresentam alguma evolução e as relações familiares adquirem maior flexibilidade em sua dinâmica.

\section{Objetivos}

\section{Geral:}

Proporcionar espaço para abordar aspectos emocionais e comportamentais associados à obesidade estabelecendo possíveis relações com as dificuldades na adesão ao tratamento.

\section{Específicos:}

Para o grupo de jovens:

Propiciar um espaço para expressão de sentimentos e pensamentos a respeito da obesidade e reflexão sobre posturas e atitudes 
adotadas em relação ao tratamento, com vistas à modificação de comportamento.

\section{Para o grupo dos pais/responsáveis:} Oferecer um espaço para expressão de sentimentos e percepções a respeito da queixa clínica dos jovens, relacionando-os às dificuldades envolvidas na orientação e na condução do tratamento, visando a mudanças comportamentais.

\section{Metodologia}

O grupo teve sua formação a partir dos casos encaminhados pela equipe de endocrinologia, que utilizou como critério o IMC (índice de massa corporal), que é a relação entre peso em quilos e a estatura em metros quadrados. Os resultados são comparados com tabelas de percentis segundo sexo, idade e raça. O IMC acima do percentil 85 e abaixo do percentil 95 é considerado como sobrepeso, e, a partir do percentil 95, como obesidade.

O passo inicial foi o contato telefônico com os responsáveis para agendar o primeiro encontro, visto que as informações iniciais sobre a participação no grupo já tinham sido fornecidas em consulta médica. O grupo foi formado inicialmente por sete pacientes com idades entre 8 e 15 anos, sendo cinco do sexo masculino e dois do sexo feminino, de nível socioeconômico médio-baixo e escolaridade compatível com a faixa etária. Houve uma desistência no primeiro encontro e outra posteriormente. Cada paciente viera acompanhado por um responsável, sendo que, em um único caso, compareceram o pai e a mãe juntos. Ao longo dos encontros, alguns pais/responsáveis revezaram na presença.

Por tratar-se de uma proposta de trabalho que faria parte da rotina de atividades do serviço de psicologia da instituição, o projeto não foi submetido ao Comitê de Ética. No entanto, os pais/responsáveis e os próprios pacientes foram previamente informados sobre os objetivos do trabalho, sobre a questão do sigilo das informações bem como da possibilidade de desistência do grupo a qualquer momento sem prejuízo do tratamento. Após as orientações, os participantes assinaram o Termo de Consentimento Livre e Esclarecido.

O trabalho consistiu na realização de sete encontros com a frequência de uma vez por semana, sempre no mesmo dia, com duração de 1 hora. Uma estagiária coordenava o grupo de pais/responsáveis e a outra, o grupo dos pacientes. Primeiramente, foi realizado um levantamento bibliográfico a respeito da temática principal: obesidade. Em seguida, foram eleitos os temas a serem abordados e selecionadas as dinâmicas de grupo que atendessem aos objetivos específicos de cada encontro. No entanto, permitiu-se uma certa flexibilidade para alterar o tema proposto caso as questões trazidas pelos participantes no encontro anterior merecessem maior aprofundamento.

Nos encontros, foram utilizadas dinâmicas de grupo baseadas no referencial psicodinâmico, no uso de recursos gráficos e nas discussões sobre temas específicos. A seguir, descreveremos os encontros grupais com os pacientes e com os pais/responsáveis e seus respectivos objetivos.

\section{Com os pacientes:}

O primeiro encontro teve como intuito apresentar a proposta de trabalho ao grupo e verificar o seu interesse e comprometimento, uma vez que seria necessária a presença semanal. Realizou-se uma atividade gráfica que consistia em fazer um desenho da família e posteriormente apresentá-lo aos demais participantes. Em seguida, explicou-se o objetivo do grupo, sendo possível perceber as expectativas de cada um para o trabalho que seria ali realizado. Ao final da apresentação, a Carta de Consentimento Livre e Esclarecido foi lida e por eles assinada. 
No segundo encontro, o objetivo foi abordar a questão da ansiedade; para isso, realizou-se uma atividade em que, no primeiro momento, cada participante deveria desenhar uma estrela de seis pontas, sendo que cada ponta representava uma pergunta relacionada ao tema. Em um segundo momento, deveriam chegar a um consenso a respeito das questões, respondendo-as em uma estrela coletiva. No encontro posterior, foi retomada a atividade feita na semana anterior, aprofundando-se o tema relativo à ansiedade.

No quarto encontro, o objetivo de ambos os grupos foi trabalhar a autoimagem real e ideal e a ideia de como eram vistos pelos outros. Com os pacientes, foi proposta uma atividade em que identificariam, em fotos de revistas, a imagem que tinham de si, o ideal de imagem e a forma como imaginavam que os outros os viam. No quinto encontro, o objetivo era trazer para mais perto dos pacientes a responsabilidade por sua saúde. Para isso, a dinâmica realizada consistia em primeiramente levantar problemas, escrevêlos e colocá-los dentro de bexigas, que seriam trocadas entre os participantes, sendo que cada um deveria propor possíveis soluções para o problema encontrado.

No sexto encontro com os pacientes, a proposta era continuar trabalhando a responsabilização de cada um por sua saúde e tratamento, e, para tanto, foi realizada uma atividade em que poderiam comprar o que desejassem, porém teriam que pagar com algo em troca. Os produtos consistiam em cartões previamente elaborados pela estagiária relacionados às emoções e estética. Já a moeda de troca era elaborada pelos pacientes de acordo com o que estivessem dispostos a negociar. O sétimo e último encontro, em ambos os grupos, foi destinado a avaliar o trabalho, por meio de um questionário elaborado pelas estagiárias, além de promover um encerramento do grupo. Nos dois grupos, realizou-se uma discussão a partir das respostas fornecidas. No grupo de pacientes, foi desenvolvida uma dinâmica em que cada participante recebia uma figura de mala, na qual deveriam escrever o que desejariam levar dos encontros, podendo ainda escrever do lado de fora o que gostariam de deixar, encerrando-se, assim, as atividades.

\section{Com os pais/responsáveis}

No grupo de pais/responsáveis, procurou-se realizar a integração através de uma breve apresentação pessoal e familiar por meio do qual foram colhidos dados relevantes sobre os pacientes. Estabeleceu-se o contrato de participação, foram discutidas as expectativas e, por fim, foi apresentada a Carta de Consentimento Livre e Esclarecido para assinatura.

No segundo encontro, foi possível ter o feedback dos responsáveis quanto à disposição dos filhos(as) e deles mesmos em seguir participando. Com o objetivo de abordar os temas mútua dependência, colaboração e cooperação, direcionando a questão para a dinâmica familiar, foi realizada uma atividade gráfica em dupla com a seguinte orientação: uma pessoa desenharia uma casa, enquanto a outra daria as instruções desse desenho; no entanto, quem desenhasse estaria com os olhos fechados e não poderia falar, e quem desse as instruções só poderia se manifestar verbalmente e não tocar na outra pessoa nem na folha.

No terceiro encontro, o objetivo principal foi abordar o tema limites a partir de frases previamente elaboradas sobre situações do cotidiano. Debateram-se as dificuldades da dependência mútua dentro da dinâmica familiar e a questão da autoridade $x$ autoritarismo. A cada momento da atividade, as questões trazidas pelos pais/responsáveis eram valorizadas e incentivadas a serem compartilhadas com os demais participantes 
com o intuito de promover uma reflexão baseada em suas próprias experiências. Eventualmente, quando não era possível esgotar a discussão no próprio encontro, os seguintes serviam a esse propósito.

No quarto encontro, foi conduzida uma dinâmica que consistia em provocar reflexão através de perguntas sobre a forma como se viam no papel de pais/avós, como imaginavam que o(a) filho(a) os viam e como gostariam de serem vistos. No quinto encontro do grupo, foi retomado o encontro anterior e dada continuidade à segunda parte da dinâmica. O objetivo dessa vez foi abordar as diferentes formas como os filhos são vistos através de uma atividade lúdica, na qual representariam no papel, por meio de gravuras, frases ou desenhos de como veem seu filho(a), como imaginam que o próprio filho(a) se vê e como acreditam que os outros veem o filho(a).

No sexto encontro, foi dada continuidade à proposta anterior, e, a partir das montagens produzidas pelos participantes, retomou-se a discussão sobre a relação imagem real x imagem ideal e sobre a importância da contribuição dos familiares na condução do tratamento. Nesse encontro, ainda fora relembrada a questão do desligamento na semana posterior. $\mathrm{O}$ encerramento foi dado através da atividade de compartilhar heranças do grupo, o que levavam do grupo em termos de aprendizado e o que deixavam em termos de contribuição.

\section{Resultados}

\section{Grupo de pacientes}

O primeiro encontro com os pacientes possibilitou o levantamento das expectativas que os mesmos traziam para o grupo, sendo possível identificar uma visão até certo ponto idealizada dos objetivos que se evidenciou como solução mágica para a questão da obesidade. Além disso, foi possível notar que, apesar das diferenças em relação às idades dos pacientes, ocorreu bom entrosamento, ficando viável a proposta do grupo.

A execução da atividade proposta para o segundo encontro foi mais extensa do que o esperado, e, por esse motivo, apenas a definição da palavra ansiedade pôde ser discutida. Foi interessante notar como o tema obesidade veio à tona sem ter sido trabalhado diretamente, já que fizeram a relação direta entre ansiedade como um sentimento ruim e o excesso de alimento. Dessa forma, foi possível debater um pouco tal aspecto, porém a discussão precisou ser interrompida devido ao horário.

No terceiro encontro com os pacientes, a discussão foi retomada, e foi possível verificar a forma como os pacientes respondiam a situações geradoras de ansiedade, relacionando-as à comida ou a comportamentos passivos, tais como assistir televisão, jogar vídeo-game ou ficar muito tempo no computador. Foi possível discutir sobre novas formas de lidar com a ansiedade e com os sentimentos, o que levou os próprios pacientes a argumentarem, questionarem e apresentarem outras possibilidades, o que tornou o encontro muito enriquecedor.

A atividade proposta para o quarto encontro conseguiu atingir de maneira satisfatória o objetivo, pois os participantes puderam dizer abertamente o que pensavam a respeito de si mesmos e dos outros em relação a eles, ficando evidente o desejo de corresponder ao modelo de beleza imposto pela mídia. Outra questão que surgiu foi o desejo de resolver os problemas de forma rápida, tendo citado como exemplo a cirurgia de redução de estômago como algo que resolveria instantaneamente a obesidade.

No quinto encontro, os pacientes expuseram aquilo que consideravam problema, e, mais uma vez, a questão da obesidade foi muito 
abordada; em seguida, cada um deles teve que propor uma solução, o que possibilitou a troca de ideias bem como a desmistificação de alguns pontos, tais como: o fato de a felicidade estar diretamente ligada à beleza física ou a possibilidade de livrar-se do que incomoda sem nenhum esforço.

A proposta do sexto encontro permitiu exemplificar o custo necessário para se conseguir o que se deseja, nesse caso, os esforços necessários para emagrecer. Tal atividade serviu como forma mais concreta de perceber que as soluções não são mágicas como gostariam, mas, ao mesmo tempo, a atividade pareceu abrir a possibilidade de se conseguir o que é desejado, desde que haja responsabilidade e compromisso.

No último encontro, foi possível avaliar a eficácia do grupo por meio das respostas obtidas no questionário, podendo-se notar que o grupo serviu para que os pacientes pudessem repensar algumas de suas atitudes. Além disso, possibilitou o encerramento e a despedida dos pacientes de maneira bastante agradável.

\section{Grupo pais/responsáveis}

No primeiro encontro com pais/responsáveis, foi possível observar que lhes agradou a proposta do grupo, o que resultou em um comprometimento quanto à participação nos encontros seguintes. Houve entrosamento entre os participantes, que, já de início, expuseram opiniões e mencionaram dificuldades, o que permitiu um bom andamento do encontro de apresentação. Os pais/ responsáveis suscitaram ainda temas como a importância da adesão ao tratamento e a influência dos aspectos emocionais, e, dessa forma, o encontro alcançou o seu objetivo inicial.

No segundo encontro, a atividade gráfica da casa provocou uma discussão produtiva a respeito da dependência e da colaboração com o tratamento do paciente. A atividade propiciou um clima de descontração, permitindo que os participantes ficassem mais à vontade para se expressarem, tendo surgido temas como: as regras e as dificuldades em seguí-las, disposição de ambas as partes e falhas na comunicação e falta de diálogo, fatores que dificultam o alcance dos resultados esperados. Assim, puderam refletir sobre suas posturas diante do tratamento do paciente. A atividade gráfica ainda trouxe resultados válidos mencionados por alguns participantes em encontro posterior.

No terceiro encontro, foi debatido o tema limites, sendo possível perceber quais têm sido as atitudes dos pais/responsáveis, o quanto são permissivos ou não e a importância da colaboração efetiva. A discussão possibilitou a abordagem dos seguintes temas: a forma de colocar limites, que não deve ser agressiva, a desautorização de um dos pais frente aos filhos, autoridade $x$ autoritarismo, a culpa em ser firme, as consequências e as dificuldades de manter determinadas atitudes e a convivência com a frustração e a raiva decorrentes de certas atitudes dos pais. Através disso, os pais/responsáveis puderam reforçar a importância de seu papel no acompanhamento dos filhos.

O quarto encontro teve como resultado uma rica discussão sobre o papel que desempenham como pais/responsáveis. Refletiram sobre possíveis alternativas para se aproximarem, em suas atitudes, daquilo que têm como papel ideal a ser exercido, ou seja, debateram a visão real $x$ ideal, o que se considerou extremamente significativo. Diante das colocações feitas pelos participantes, foi possível notar o seu esforço em agir de maneira mais coerente com os pacientes, o que resultou em uma relação de maior proximidade. A cada encontro era possível retomar questões já abordadas, possibilitando maior fixação dos 
temas pelos participantes. Em virtude das trocas positivas de informações na discussão, a segunda parte da atividade programada para o dia foi realizada no encontro seguinte.

No quinto encontro, a atividade lúdica propiciou alcançar o objetivo de abordar as diferentes formas de como os filhos são vistos. Surgiram temas como: baixa autoestima, sensação dos filhos de serem diferentes, fuga diante do que lhes causa incômodo, dificuldade no manejo de sentimentos confusos e contraditórios, até certo ponto próprios da idade, incentivos aos filhos e, novamente, a questão da importância da colaboração de todos à volta. Comentaram atitudes dos filhos e explicaram porque os veem de determinada maneira.

O sexto encontro teve como resultado a reflexão dos participantes quanto a possíveis alternativas para a melhoria da visão que imaginam que os filhos têm de si mesmos. A atividade lúdica de colagem serviu como estímulo facilitador para que dessem vazão às suas opiniões. Ainda surgiram assuntos como: acordos entre eles e os pacientes, a importância do diálogo e da percepção que têm dos filhos, o fato de se seguir o tratamento apenas durante a semana seguinte à consulta médica e, por fim, a dependência do grupo em virtude do desejo dos participantes de dar continuidade ao trabalho. Dessa forma, foi possível atingir o objetivo do dia, que consistia em abordar o desligamento da semana posterior.

No sétimo e último encontro, avaliou-se, através do questionário, a eficácia do grupo. Os pais/ responsáveis puderam comentar brevemente suas opiniões e notou-se que a experiência do grupo trouxe resultados favoráveis aos participantes, que mencionaram mudanças na forma de agir a partir de reflexões suscitadas pelos encontros.

\section{Discussão dos resultados}

Corroborando o pensamento de Toledo (2006) sobre o atendimento grupal, pode-se afirmar que a proposta foi eficaz e que de fato funcionou como potencial de apoio e de contato entre os participantes, tendo assim proporcionado a troca de experiências que favoreceu a reflexão de posturas adotadas diante da mesma situação. A faixa etária dos pacientes que participaram do projeto (8 a 15 anos) a princípio não pareceu ser um obstáculo para a realização dos encontros; no entanto, no decorrer do processo, notou-se certa influência desse fator, visto que os dois participantes de 8 anos de idade foram os únicos que desistiram ao longo do trabalho realizado. Considerou-se que isso ocorreu devido ao fato de as atividades exigirem um nível de abstração suficiente para propiciar discussões e reflexões mais aprofundadas e, portanto, difíceis para os mais novos.

A realização de um trabalho paralelo com os pais/responsáveis contribuiu satisfatoriamente para o resultado final. Assim, ficou clara a influência dos pais no estado geral dos filhos, confirmando a ideia de Cerveny (2004) quanto à interdependência entre os vários subsistemas familiares, que considera ser o familiar tido como paciente apenas o sinalizador da dinâmica maior que abrange as relações entre todos os familiares, e que, portanto, estes devem também ser considerados. Isso justifica ainda a importância de ter sido abordado nos encontros de pais/ responsáveis o aspecto da mútua cooperação no tratamento.

Nas atividades realizadas, foi possível verificar ainda posturas que estavam sendo adotadas pelos pais/responsáveis e que iam ao encontro das colocações de Risi e Teixeira (1999) a respeito da dificuldade de impor limites por parte aqueles que cuidam da criança, o que implica lidar e atualizar suas próprias questões relacionadas a esse tema. Ainda com relação às atitudes apresentadas pelos pais/ responsáveis, percebeu-se a necessidade de refletir sobre o cuidado que se deve ter em não adotar uma posição extrema, isto é, em 
não vê-lo como alguém que está condenado a ser assim e a discriminá-lo, ou então como alguém que não tem força de vontade com relação à perda de peso, assim como postulam Ballone e Moura (2007). Outro aspecto mencionado por esses autores e percebido nas atividades e falas dos pacientes refere-se às condições da vida moderna como facilitadoras do fato de a obesidade se tornar cada vez mais frequente durante a infância e a adolescência. Um fator que exemplifica isso e que foi citado tanto pelos pacientes como pelos pais/responsáveis é o excessivo tempo que ficam sentados diante da TV e do computador, diminuindo a prática de exercícios físicos.

Tendo em vista a forma de lidar com a ansiedade trazida pelos pacientes, que, em situações geradoras de ansiedade sentem maior necessidade de comer, pode-se considerar como válida a colocação de Mello Filho (2000) que se refere aos obesos como aqueles que basicamente têm a comida como linguagem. Dessa forma, o sedentarismo caracterizado acima, aliado a essa maior necessidade de comer, contribuem para manter o sobrepeso. De acordo com Ballone, há um processo contínuo de desenvolvimento do aparelho psíquico entre as várias fases da vida da criança e do adolescente, e, nessa fase difícil de mudanças e de afirmações pela qual o jovem passa, a autoridade pode adquirir espaço importante, por isso a importância de pais/responsáveis entenderem a diferença entre autoridade e autoritarismo, além de saberem como se colocar diante do paciente, como impor limites e colaborar no tratamento. Tais aspectos foram abordados nos encontros e servem para reafirmar a pertinência do grupo paralelo com pais/responsáveis.

Ballone observa que existem mecanismos mais complexos relacionados com as experiências psicológicas que regulam o processo de alimentação. Dessa forma, podemos afirmar que as situações vivenciadas pelas crianças e jovens, como ser alvo de comentários, ter sentimentos de culpa e sofrer desaprovações, entre outras, influenciam o quadro clínico de obesidade, como pôde ser observado nas falas de alguns pacientes.

Durante o processo, alguns familiares se revezaram na frequência às atividades propostas, o que ocasionou um efeito ambíguo. Assim, ao mesmo tempo em que se pôde sensibilizá-los a partir de uma reflexão sobre a colaboração de todos no processo, que permitiu diferentes visões relativas ao mesmo paciente, também foi dificultada a continuidade aos encontros, pois, a cada novo participante, fazia-se necessário situálo quanto às atividades que vinham sendo realizadas dentro da proposta do grupo.

É importante ressaltar, ainda, que o hospital no qual o projeto foi desenvolvido estava em reforma, o que acarretou a indisponibilidade de um espaço fixo para a realização dos encontros. Em consequência, a cada semana, o grupo se reunia em lugares distintos, porém sempre em salas em condições satisfatórias de uso e que garantissem, portanto, a privacidade e a confidencialidade necessárias ao desenvolvimento da atividade.

Outra questão institucional a ser considerada relaciona-se à nomeação dada ao grupo pela equipe de funcionários do ambulatório: grupo de obesos, denominação que foi encarada pelos participantes com certo desagrado, já que traz uma conotação negativa. Em virtude de tal situação, fez-se necessário abordar o significado da palavra obesidade e o impacto que esta gera nos pacientes, a fim de que tal acontecimento não fosse entendido como forma de discriminação, visto que, segundo Allon (1979) e Ballone e Moura (2007), o paciente com obesidade se sente discriminado, conforme já mencionamos, o que interfere em seus relacionamentos sociais. 
De acordo com Gomes (1994) e Outeiral (2003), a questão da depreciação da autoimagem se torna bastante presente quando se fala em crianças e adolescentes com diagnóstico de obesidade. Isso foi verificado nas discussões realizadas entre os pacientes, que expressaram a dificuldade de aceitar a aparência e a condição física, chegando a evitar olharem-se no espelho e buscarem sempre o ideal de beleza. Essa aparente insegurança e a busca de aceitação também são apontadas por autores como itens frequentes.

As mensagens educativas dirigidas aos jovens estimulam a ideia de que uma boa imagem é suficiente para a obtenção de êxito tanto na vida social como profissional e familiar, conforme observa Ballone. Dessa forma, o jovem será influenciado por elas, e, ao ver que não corresponde a esse padrão, não se sentirá aceito socialmente, o que traz dificuldades para o dia a dia, como pôde ser abordado em alguns encontros.

Segundo Assis, Avanci, Silva, Malaquias, Santos e Oliveira (2003), os jovens com elevada autoestima demonstram capacidade para lidar com desafios e conseguem se adaptar mais facilmente a uma situação, pois acreditam na sua competência. Já os jovens com baixa autoestima são mais sensíveis a críticas dirigidas a eles e tendem a apresentar sentimentos de inferioridade, isolamento e insegurança. Considerando tais informações, é extremamente válida a abordagem da autoimagem dos pacientes e de todos os aspectos emocionais envolvidos.

Com relação aos pais/responsáveis, também foi observada insegurança, no entanto, referente à forma como imaginam que os filhos são vistos, o que vem novamente ao encontro da afirmação de Gomes (1994), que aborda o sentimento de insegurança em relação aos outros ao imaginarem que serão sempre vistos com hostilidade e desprezo.
Isso poderia acentuar o preconceito já citado pelos autores Allon (1979) e Ballone e Moura (2007). Por fim, quanto às mudanças no relacionamento familiar, os resultados observados nos encontros são congruentes com as considerações de Toledo (2006), de que a abordagem grupal melhora o relacionamento familiar, isto é, a experiência traz transformações benéficas para a dinâmica familiar como um todo.

\section{Conclusão}

A experiência relatada ilustrou a importância de abordar os aspectos emocionais presentes na obesidade, favorecendo uma visão mais ampla do paciente por meio de um atendimento interdisciplinar, visto que a obesidade tem etiologia multifatorial. Os objetivos da proposta inicial foram alcançados, trazendo resultados satisfatórios aos encontros e levando-nos a concluir que o atendimento grupal, ao possibilitar que os participantes compartilhem vivências e debatam sobre suas atitudes, facilita a reflexão sobre as posturas adotadas e contribui para mudanças mais duradouras.

A efetivação de um trabalho assim só é possível quando, além do conhecimento técnico, o profissional estabelece um vínculo verdadeiro com o paciente, favorecendo uma relação mais autêntica. Para os pais/ responsáveis, pacientes e profissionais envolvidos nesse trabalho, a experiência foi válida por trazer resultados positivos, e pode ser reaplicada em outros contextos. A equipe pôde observar que houve uma diminuição das faltas às consultas e, em alguns casos, sensível redução de peso, além de maior envolvimento e comprometimento dos familiares com o tratamento. Dessa forma, o trabalho da Psicologia se tornou efetivamente parte integrante do tratamento de crianças e adolescentes obesos ou com sobrepeso dessa instituição hospitalar.

Diante da avaliação do desenvolvimento e da realização do grupo, considera-se importante 
ressaltar que a possibilidade de existir uma entrevista de triagem para a formação do grupo seria válida, pois dessa forma seriam observados cuidadosamente aspectos como maturidade emocional, nível emocional e possível envolvimento nas atividades planejadas, entre outros, a fim de promover melhor entrosamento dos participantes, maior aproveitamento e menor índice de desistências.

Com a existência dessa entrevista prévia, será possível esclarecer melhor aos participantes a proposta do atendimento grupal e sanar dúvidas, visto que nem sempre os pacientes chegam conhecendo os objetivos do trabalho, ainda que tenham sido informados pela equipe médica por ocasião do encaminhamento. Sugere-se também que os temas e as atividades sejam previamente selecionados, mas determinados conforme o andamento semanal do grupo, como na proposta apresentada, uma vez que a formação de cada grupo será sempre única, sendo necessário, portanto, conhecer a dinâmica de cada grupo e adequar a ela as atividades.

Quanto à condução dos atendimentos grupais ser feita em dupla, sugere-se que seja mantida, pois o atendimento feito por uma única pessoa, com os grupos separados, pode vir a fragilizar o vínculo de confiança estabelecido.

Notada a importância do tema explorado e os bons resultados encontrados, julga-se pertinente o incentivo à continuidade de estudos e pesquisas na área, por tratar-se de um campo fértil e, ao mesmo tempo, carente de trabalhos específicos. 


\section{Aline Attene de Almeida Bayer * \\ Graduada pela Universidade Presbiteriana Mackenzie, São Paulo - SP - Brasil. \\ E-mail: alineattene@ig.com.br}

\section{Camila Carrascoza Vasco}

Graduada pela Universidade Mackenzie, São Paulo - SP - Brasil.

E-mail: camilavasco@yahoo.com.br

\section{Sandra Ribeiro de Almeida Lopes}

Doutora em Ciências da Saúde pelo Instituto de Psicologia da Universidade de São Paulo - SP - Brasil. E-mail: salmeidalopes@mackenzie.br

\section{Cristina Jeldes Carrascosa Teixeira}

Especialização em psicologia da infância.

E-mail: crisjeldes@yahoo.com.br

\section{*Endereço para envio de correspondência:}

Universidade Presbiteriana Mackenzie - Curso de Psicologia

Rua da Consolação, 896 - Consolação, Prédio 38 São Paulo, SP - Brasil. CEP 01302-907.
Allon, N. (1979). Self-perceptions of stigma of overweight in relation to weight-patterns. The American Journal of Clinical Nutrition, 32, 470-80.

Assis, S. G., Avanci, J. Q., Silva, C. M. F. P., Malaquias, J. V., Santos, N. C., \& Oliveira, R. V. C. (2003). A representação social do ser adolescente: um passo decisivo na promoção de saúde. Ciência e Saúde Coletiva, 8(3), 669-679. Recuperado em outubro de 2008, de http://www.scielosp.org/scielo. php?pid $=$ S1413-81232003000300002\&script $=$ sci arttext\&tlng $=\mathrm{pt}$

Ballone, G. J., \& Moura, E. C. (2007). Obesidade. In PsiqWeb. Recuperado em outubro de 2008, de http://www.psiqweb. med.br

Ballone, G. J. (2007). Transtornos alimentares. In PsiqWeb. Recuperado em outubro de 2008, de http://www.psiqweb. med.br/

Cardoso, L. K. O., \& Carvalho, A. M. P. (2007). Avaliação psicológica de crianças acompanhadas em programa de atenção multiprofissional à obesidade. Interface, 11 (22), 297 312. Recuperado em outubro de 2008, de www.scielo.br/ scielo.php?pid $=$ S1414-32832007000200009\&script $=$ sci arttext\&tlng=es

Carvalho, A. M., Cataneo, C., Galindo, E. M. C., \& Malfará, C. T. (2005, janeiro/abril). Autoconceito e imagem corporal em crianças obesas. Paidéia, 15, 30.

Cerveny, C. M. O. (Ed.). (2004). Família e... São Paulo: Casa do Psicólogo.

Denzer, C., Reithofer, E., Wabitsch, M., \& Widhalm, K. (2004). The outcome of childhood obesity management depends highly upon patient compliance. European Journal of Pediatrics, 163, 99-104.

Ferriani, M. G., Dias, T. S., Silva, K. Z., \& Martins, C. S. (2005, janeiro/março). Auto-imagem corporal dos adolescentes atendidos em um programa multidisciplinar de assistência ao adolescente obeso. Revista Brasileira de Saúde Materno Infantil, 5(1), 27-33. Recuperado em outubro de 2008, de http://www.scielo.br/scielo.php?pid=S1519$38292005000100004 \&$ script=sci_arttext\&tlng=pt

Gomes, R. A. (1994). Análise de dados em pesquisa qualitativa. In M. C. S. Minayo (Ed.), Pesquisa social: teoria, método e criatividade (4a ed., pp. 67-80). Petrópolis, RJ: Vozes.

Grazini, J., \& Amancio, O. M. S. (1998, março). Analogia entre comerciais de alimentos e hábito alimentar de adolescente. The Electronic Journal of Pediatric Gastroenterology, Nutrition Liver Diseases, 2(1), 1-14.

Klesges, R. C., Shelton, M. L., \& Klesges, L. M. (1993, fevereiro). Effects of television on metabolic rate: Potential implications for childhood obesity. Pediatrics, 91(2), 281-286.

Kochi, C. \& Monte, O. (2006, março/abril) Epidemia de alta complexidade e graves conseqüências:obesidade infantil. Nutrição Profissional, 2, 6.

Mello, E. C., Luft, V. C., Meyer, F. (2004). Atendimento ambulatorial individualizado versus programa de educação em grupo: qual oferece mais mudança de hábitos alimentares e de atividade física em crianças obesas? Jornal de Pediatria, 80(3), 468-474

Mello Filho, J. (Ed.). (2000). Grupo e corpo: psicoterapia de grupo com pacientes somáticos. Porto Alegre: Artes Médicas Sul.

Outeiral, J. (2003). Adolescer - estudos revisados sobre adolescência (2a ed., rev., atual. e ampl.). São Paulo: Revinter.

Teixeira, A. S., \& Risi, V. (1999). Agressividade ou falta de limites? In Educação. Guia do bebê. Recuperado em outubro de 2008, de http://guiadobebe.uol.com.br/bb2a3

Toledo, R. P. (2006, dezembro). A experiência de atendimento a um grupo de familiares em um centro de atenção psicossocial infantil. Vínculo, 3.

Vasques, F., Martins, F. C., \& Azevedo, A. P. (2004). Aspectos psiquiátricos no tratamento da obesidade. Revista de Psiquiatria Clínica, 31(4), 195-198. Recuperado em outubro de 2008, de http://www.scielo.br/scielo.php?pid=S0101$60832004000400013 \&$ script $=$ sci arttext 